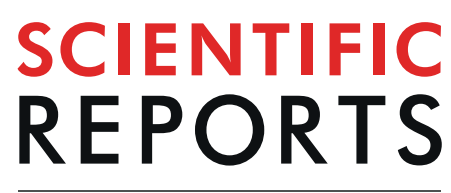

natureresearch

\title{
The evolution of zebrafish RAG2 protein is required for adapting to the elevated body temperature of the higher endothermic vertebrates
}

\begin{abstract}
Ao Sun ${ }^{1,5}, \mathrm{Ke} \mathrm{Xu}^{1,5}$, Haifeng Liu ${ }^{1}$, Hua Li ${ }^{1}$, Yaohuang Shi ${ }^{1,2}$, Xiaoyan Zhu ${ }^{1}$, Tao Liang ${ }^{1}$, Xinyue $\mathrm{Li}^{1}$, Xianxia Cao ${ }^{1,2}$, Yanhong $\mathrm{Ji}^{3}$, Taijiao Jiang ${ }^{4}$, Chenqi $\mathrm{Xu}^{1}$ \& Xiaolong $\mathrm{Liu}^{1,2^{*}}$

The recombination activating gene (RAG or RAG1/RAG2 complex)-mediated adaptive immune system is a hallmark of jawed vertebrates. It has been reported that RAG originated in invertebrates. However, whether RAG further evolved once it arose in jawed vertebrates remains largely unknown. Here, we found that zebrafish RAG (zRAG) had a lower activity than mouse RAG (mRAG). Intriguingly, the attenuated stability of zebrafish RAG2 (zRAG2), but not zebrafish RAG1, caused the reduced $\mathrm{V}(\mathrm{D}) \mathrm{J}$ recombination efficiency compared to $\mathrm{mRAG}$ at $37^{\circ} \mathrm{C}$ which are the body temperature of most endotherms except birds. Importantly, the lower temperature $28^{\circ} \mathrm{C}$, which is the best temperature for zebrafish growth, made the recombination efficiency of zRAG similar to that of mRAG by improving the stability of zRAG2. Consistent with the prementioned observation, the V(D)J recombination of $\operatorname{Rag} 2^{\mathrm{K} I / \mathrm{KI}}$ mice, which zRAG2 was substituted for MRAG2, was also severely impaired. Unexpectedly, Rag2 $2^{\mathrm{KI} / \mathrm{KI}}$ mice developed cachexia syndromes accompanied by premature death. Taken together, our findings illustrate that the evolution of zebrafish RAG2 protein is required for adapting to the elevated body temperature of the higher endothermic vertebrates.
\end{abstract}

Jawed vertebrates possess a diverse repertoire of T cell receptors (TCRs) and immunoglobulins (Igs) to specifically recognize and ultimately destroy unlimited numbers of foreign and lethal invaders or pathogens ${ }^{1-3}$. TCRs and Igs are assembled via the recombination of variable (V), diversity (D), and joining (J) gene segments ${ }^{3-5}$. The $\mathrm{V}(\mathrm{D}) \mathrm{J}$ recombination is a cut-and-paste reaction mediated by the RAG1/RAG2 complex (RAG) within specific genomic recombination signal sequence (RSS) sites ${ }^{3,4,6}$. Therefore, RAG triggers the TCR- and Ig-based adaptive immune system of jawed vertebrates to defense foreign invaders ${ }^{7,8}$.

In recent decades, many scientists have carefully explored the origin of $\mathrm{RAG}^{8-10}$. Our previous study has shown that bfRAG1L, an amphioxus RAG1-like DNA fragment, encodes a functional central domain of the vertebrate core RAG $1^{9}$. Another study found that RAG1 originated from the Transib transposase and could independently mediate $\mathrm{V}(\mathrm{D}) \mathrm{J}$ recombination ${ }^{10}$. An interesting discovery was that of amphioxus ProtoRAG, which was demonstrated to be a cut-and-paste DNA transposon from amphioxus, placing the origination of RAG as far back as in basal chordates ${ }^{8}$.

Although the origin of RAG has been well studied, however, it has remained largely unknown whether RAG in jawed vertebrates from ectotherms to endotherms further evolved. The most evolutionarily ancient living jawed vertebrates are cartilaginous fish (e.g., horned sharks), which have been verified to have a complete set of RAGs, TCRs and Igs ${ }^{2,11}$. When lower jawed vertebrates evolved into higher jawed vertebrates, they faced not only the transition in themselves from ectothermy to endothermy but also the transition in environment from aquatic to terrestrial. This process occurred along with numerous environmental changes associated with air,

\footnotetext{
${ }^{1}$ State Key Laboratory of Cell Biology, Shanghai Institute of Biochemistry and Cell Biology, Center for Excellence in Molecular Cell Science, Chinese Academy of Sciences, University of Chinese Academy of Sciences, Shanghai, 200031, China. ${ }^{2}$ School of Life Science and Technology, ShanghaiTech University, Shanghai, 201210, China. ${ }^{3}$ Department of Pathogenic Biology and Immunology, School of Basic Medical Sciences, Xi'an Jiaotong University Health Science Centre, Xi'an, Shaanxi, 710061, China. ${ }^{4}$ Center of System Medicine, Institute of Basic Medical Sciences, Chinese Academy of Medical Sciences \& Peking Union Medical College, Beijing, 100005, China. ${ }^{5}$ These authors contributed equally: Ao Sun and KeXu. *email: liux@sibcb.ac.cn
} 
water, temperature, humidity, ion concentrations, pathogenic microorganisms and body temperature $\left(\mathrm{T}_{\mathrm{b}}\right)^{12,13}$. For such great changes, we want to explore whether the adaptive immune system of jawed vertebrates, especially its hallmark RAG, evolved.

Before investigating whether there existed difference among jawed vertebrate RAG, we selected two species that are zebrafish (Danio rerio) and mice (Mus musculus) spanning the most vertebrate evolutionary history, and they are well characterized and widely used model animals ${ }^{14-17}$. Our results showed that the recombination efficiency of zebrafish RAG (zRAG) was lower than that of mouse RAG (mRAG) at $37^{\circ} \mathrm{C}$. Further research demonstrated that zRAG2, but not zRAG1 contributed to the lower recombination efficiency of zRAG compared to mRAG2 and it was due to its instability at $37^{\circ} \mathrm{C}$. Remarkably, when we moved the cells to the lower temperature $28^{\circ} \mathrm{C}$, which is the best temperature for the growth and staging of zebrafish, there was no difference between the zRAG2 and mRAG2 proteins regardless of their stability and enzymatic activity. In addition, to dissect what would have happened if RAG2 had not evolved from ectotherm RAG2, we generated the Rag2 ${ }^{\mathrm{KI} / \mathrm{KI}}$ mice, in which zRAG2 was substituted for mRAG2. Consistent with previously mentioned observation, we found that the V(D) $\mathrm{J}$ recombination efficiency of Rag $2^{\mathrm{KI} / \mathrm{KI}}$ mice was severely attenuated. To our surprise, Rag $2^{\mathrm{KI} / \mathrm{KI}}$ mice developed cachexia syndromes accompanied by premature death. Collectively, our findings suggest that the evolution of zebrafish RAG2 protein is required for adapting to the elevated body temperature of the higher endothermic vertebrates.

\section{Results}

The recombination efficiency of zRAG is lower than that of $\mathrm{mRAG}$ at $37^{\circ} \mathrm{C}$. Before investigating whether there existed evolution among jawed vertebrate RAGs, we first sought to determine whether there are functional differences among RAGs of jawed vertebrates. We selected two species whose evolution occurred four to five hundred of million years apart: the zebrafish and the mouse, which are a teleost fish and a mammal, respectively $^{14,17-19}$. A GFP reporter recombination assay and the semi-quantitative PCR method were used to evaluate the recombination efficiency of NIH3T3 and pro-B cell lines, respectively ${ }^{20-23}$. The GFP reporter recombination assay for zRAG1/zRAG2 in the NIH3T3 and HEK-293T cell lines showed that there were fewer GFP positive cells that had undergone $\mathrm{V}(\mathrm{D}) \mathrm{J}$ recombination in the zRAG1/zRAG2 group than in the mRAG1/mRAG2 group regardless of whether the cells were co-transfected with coding joint (pCJGFP) or signal joint (pSJGFP) plasmids (Fig. 1A,B and Fig. S1A,B,E). Further research showed that recombination efficiency was decreased as long as zRAG2 participated in compared with mRAG2 when they combined with zRAG1 or mRAG1 respectively; the efficiencies were as follows: mRAG1zRAG2 < mRAG1mRAG2 and zRAG1zRAG2 < zRAG1mRAG2 (Fig. 1C,D and Fig. S1C-E). Intriguingly, RAG2, but not RAG1, contributed to the attenuated recombination efficiency. Given that RAG and 12/23RSS are core components of V(D)J recombination, we next examined whether the difference in recombination efficiency between zebrafish and mice was a result of their different $12 / 23 \mathrm{RSS}$. To investigate this possibility, we substituted zebrafish 12/23RSS for mouse $12 / 23$ RSS in the pCJGFP and pSJGFP plasmids. Interestingly, we still found that recombination efficiency was decreased when zRAG2, rather than mRAG2, was combined with zRAG1 or mRAG1; the efficiencies were as follows: mRAG1zRAG $2<$ mRAG1mRAG2 and, zRAG1zRAG2 < zRAG1mRAG2 (Fig. 1E-H).

RAG is naturally expressed in B and T progenitor cells. Pro-B cells are B cell progenitors ${ }^{24,25}$. We wanted to further determine whether the decreased recombination efficiency was truly caused by zRAG2 in intact natural recombination machinery with the authentic recombination substrates within the genome and in the presence of the powerful non-homologous end joining (NHEJ) DNA repair pathway ${ }^{3}$. We performed a cell-based PCR assay to test the recombination efficiency in RAG1- or RAG2-deficient Abelson murine leukemia virus (A-MuLV)-transformed pro-B cell lines ${ }^{20,21,26}$. Consistent with our observations in the GFP reporter recombination assay with NIH3T3 cells, the levels of $\mathrm{D}_{\mathrm{H}^{-}} \mathrm{J}_{\mathrm{H}}$ rearrangement were lower in RAG2-deficient pro-B cell lines when zRAG2 was combined with mRAG1 than when mRAG2 was combined with the same mRAG1 (Fig. 1I,J). These findings suggested that RAG2, but not RAG1, reduced the recombination efficiency of zebrafish in pro-B cells at $37^{\circ} \mathrm{C}$.

The zRAG2 protein is unstable compared to the mRAG2 protein at $37^{\circ} \mathrm{C}$. We then questioned why RAG2 brought about the attenuated recombination efficiency of zebrafish. We first analyzed the mRNA expression quantity of mRAG2 and zRAG2. We found that there were no differences between them (Fig. 2A). However, the western blot results showed that zRAG2 protein expression was lower than mRAG2 protein expression (Fig. 2B). Next, we examined the biased findings based on single cell levels by FACS method ${ }^{27}$. Intriguingly, our FACS analysis showed that zRAG2 (zRAG2-GFP fusion protein) and mRAG2 (mRAG2-GFP fusion protein) exhibited similar transfection efficiencies which indicated that their amounts were not markedly different in the cells (Fig. 2C,D,F,G); however, there were distinct mean fluorescence intensity (MFI) differences in both cell lines: the MFI of zRAG2 were lower than the MFI of mRAG2 (Fig. 2C,E,F,H). In contrast, no difference was found between zRAG1 and mRAG1 with regard to either the percentage of GFP positivity or the MFI (Fig. S2A-F). Next, we further tested the protein stability in RAG2-deficient cell lines by quantifying the levels of the remaining zRAG2 and mRAG2 proteins at different time points after treating cells with the cycloheximide (CHX). The CHX chase experiment showed that the zRAG2 protein was initially unstable and had degraded by $2 \mathrm{~h}$ after the cells were placed in the $37^{\circ} \mathrm{C}$ environments (Fig. 2J,L). In contrast, mRAG2 hardly degraded and was stable throughout the experiment (Fig. 2I,K). Additionally, we found that there was no difference between zRAG1 and mRAG1 with regard to the percentage of GFP positivity or the MFI when the cells were treated with CHX or CHX plus MG132 (Fig. S2G,H). This finding suggested that the zRAG2 protein was indeed unstable compared to the mRAG2 protein at $37^{\circ} \mathrm{C}$, whereas the stabilities of zRAG1 and mRAG1 did not differ.

Next, we wanted to know if other bony fish RAG2 proteins had the similar characterization. At first, we compared the amino acid sequence of three endotherm RAG2 (Homo sapiens, Mus musculus and Rattus norvegicus) 


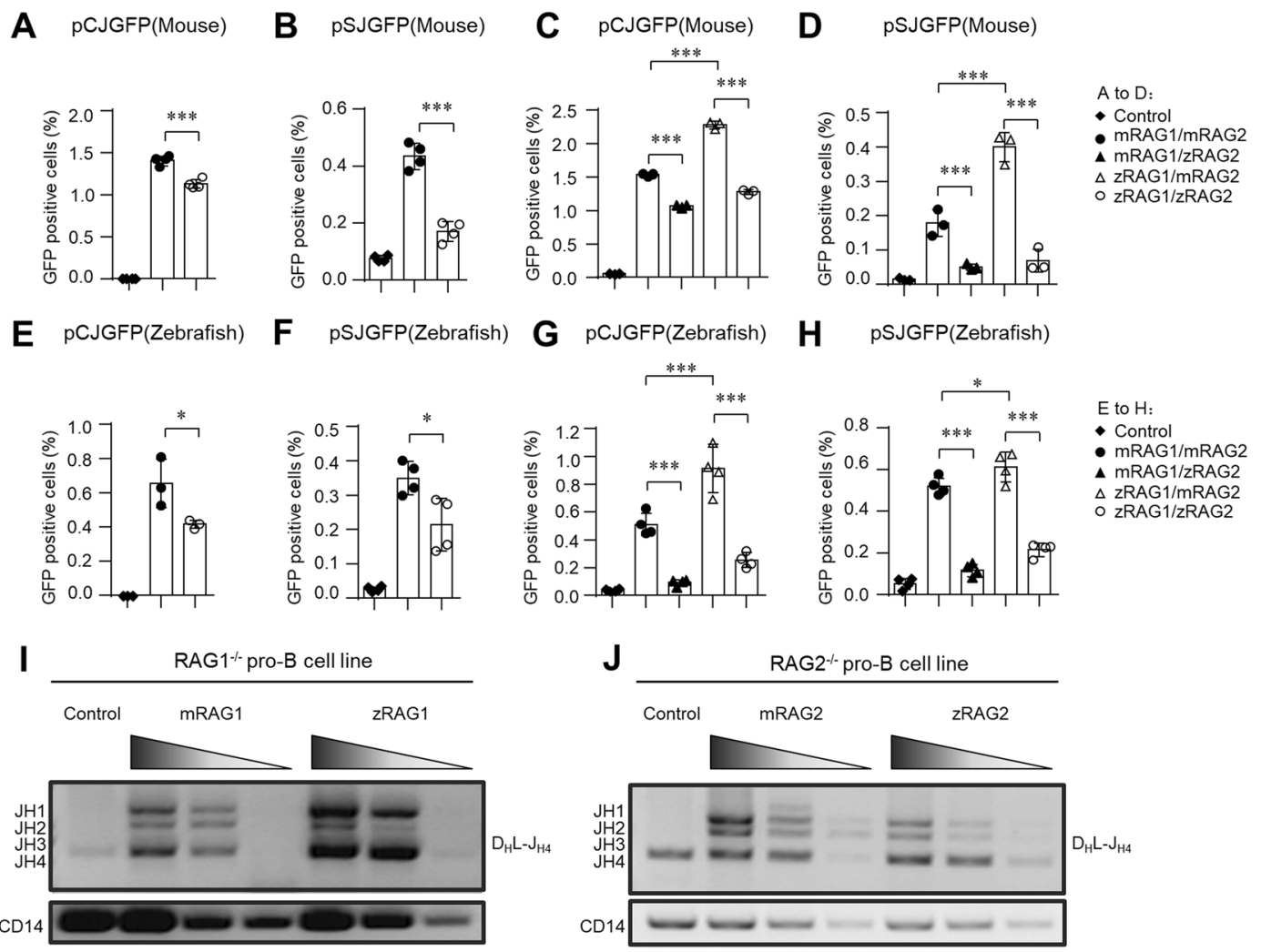

Figure 1. The recombination efficiency of zRAG is lower than that of $\mathrm{mRAG}$ at $37^{\circ} \mathrm{C}$. NIH3T3 cells were co-transfected with pCJGFP (mouse) (A,C), pSJGFP (mouse) (B,D), pCJGFP (zebrafish) (E,G) and pSJGFP (zebrafish) $(\mathbf{F}, \mathbf{H})$ and the indicated RAG1 and RAG2 using Lipo6000 transfection reagent. The GFP level was measured by flow cytometry to assess the recombination efficiency. The percentages of GFP positive cells were shown (the mean $\pm S D$ was calculated from triplicate experiments). (I,J) PCR analyses of the indicated $D_{H} J_{H}$ family rearrangements in RAG1-deficient pro-B cells (I) or RAG2-deficient pro-B cells (J). Input control: CD14 (bottom). PCR amplification was performed with fivefold serial dilutions of genomic DNA. The results are typical of three experiments. Bands related to rearrangements of various $\mathrm{J}_{\mathrm{H}}$ segments are indicated on the left. The error bars indicate the SDs. The data are presented as the mean \pm standard deviation. $* \mathrm{P}<0.05$, $* * \mathrm{P}<0.01$ and $* * * \mathrm{P}<0.001$ by Student's $\mathrm{t}$ test.

and three ectotherm RAG2 proteins (Oncorhynchus mykiss, Oreochromis niloticus and Danio rerio) (Fig. S3). We found that Oreochromis niloticus RAG2 (onRAG2), Oncorhynchus mykiss RAG2 (omRAG2) and zRAG2 proteins had sixty-four percent of identical amino acids (Fig. S3). Therefore, we try to measure RAG2 protein stability and recombination activity of another two bony fish that are onRAG2 and omRAG2. We found that onRAG2 and omRAG2 proteins were also unstable like zRAG2 (Fig. S4B) while they had similar expression level (Fig. S4A). The CHX chase experiment showed that onRAG2 and omRAG2 proteins like zRAG2 were initially unstable and had degraded by $2 \mathrm{~h}$ after the cells were placed in the $37^{\circ} \mathrm{C}$ environments (Fig. S4C). In contrast, mRAG2 hardly degraded and was stable throughout the experiment (Fig. S4C). Furthermore, the recombination efficiency of onRAG2 and omRAG2 protein was also lower than mRAG2 (Fig. S4D). These data, in combination with the characterization of zRAG2, indicated that RAG2 proteins in other teleost species were also unstable and had the lower recombination efficiency than mRAG2.

The protein stability and recombination efficiency of zRAG2 are similar to those of mRAG2 at $28^{\circ} \mathrm{C}$. We then questioned why zRAG2 was more prone to instability than mRAG2. Given that the best temperature for the growth and staging of zebrafish is approximately $28^{\circ} \mathrm{C}^{28,29}$, we sought to determine whether the stability and activity of zRAG2 was related to temperature. We first investigated zRAG2 protein stability after we moved both NIH3T3 cells and RAG2-deficient pro-B cells to a low temperature of $28^{\circ} \mathrm{C}$. To our surprise, FACS analysis showed that the MFI of zRAG2 in NIH3T3 cells was even higher than that of mRAG2 at $28^{\circ} \mathrm{C}$ (Fig. 3A,C), while the GFP expression levels had no difference between zRAG2 and mRAG2 48 hours (h) after the NIH3T3 cells had been moved from $37^{\circ} \mathrm{C}$ to $28^{\circ} \mathrm{C}$ (Fig. 3A,B). Next, we wondered what zRAG2 recombination efficiency would be since its stability was similar to that of mRAG2 at $28^{\circ} \mathrm{C}$. Interestingly, the GFP reporter recombination assay with NIH3T3 cells showed that the recombination efficiency of zRAG1zRAG2 and mRAG1zRAG2 was unexpectedly similar to that of mRAG1mRAG2 and zRAG1mRAG2 at $28^{\circ} \mathrm{C}$ (Fig. 3G). To further confirm that the role of zRAG2 in the recombination at $28^{\circ} \mathrm{C}$, we compared the mRAG1zRAG2/mRAG1mRAG2 and zRAG1zRAG2/zRAG1mRAG2 ratios at $37^{\circ} \mathrm{C}$ and $28^{\circ} \mathrm{C}$. We found that the mRAG1zRAG2/mRAG1mRAG2 and zRAG1zRAG2/zRAG1mRAG2 ratios were twice as high at $28^{\circ} \mathrm{C}$ as they were at $37^{\circ} \mathrm{C}$ (Fig. $\left.3 \mathrm{H}, \mathrm{I}\right)$. Moreover, 
A

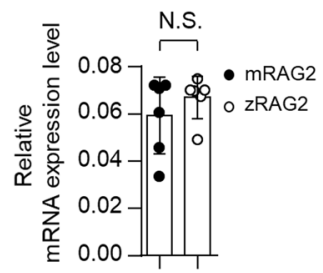

B

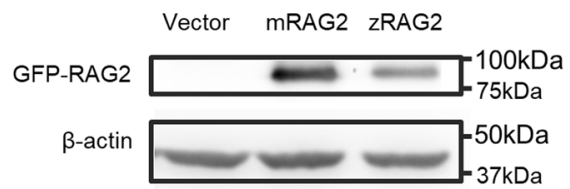

C

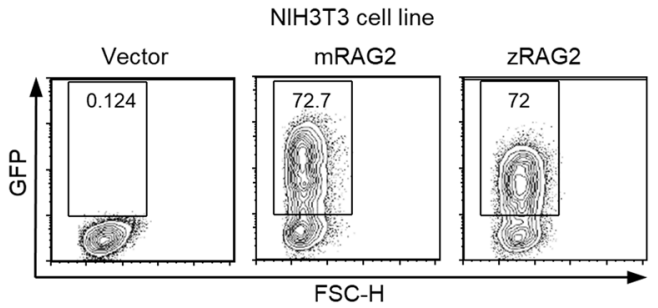

$\mathbf{F}$

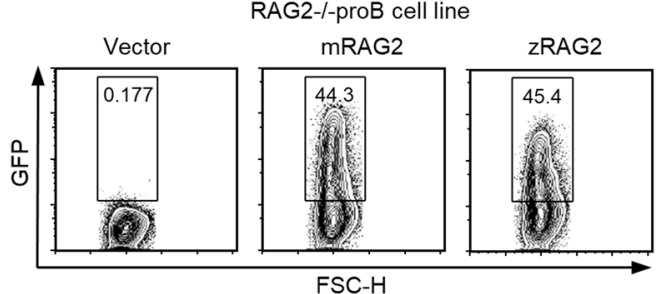

I

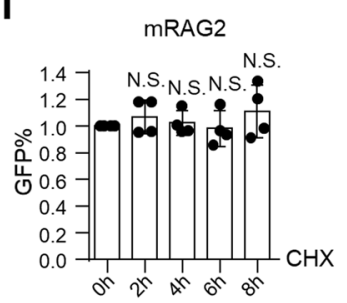

$\mathbf{J}$

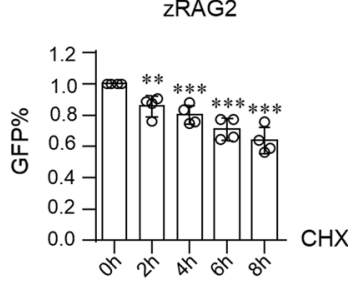

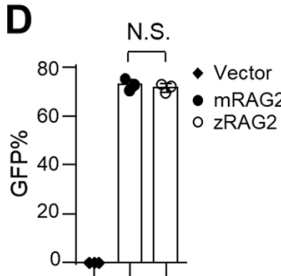

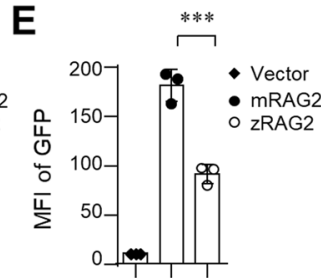

G

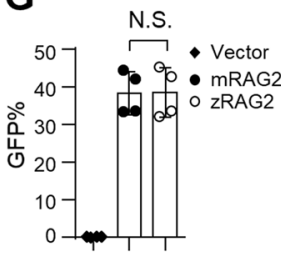

H

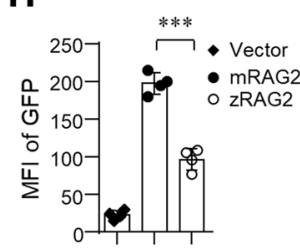

$\mathbf{L}$

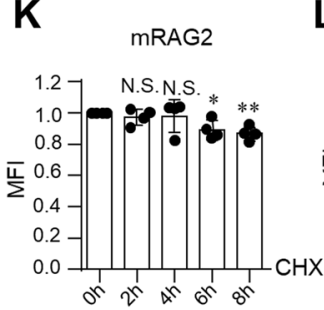

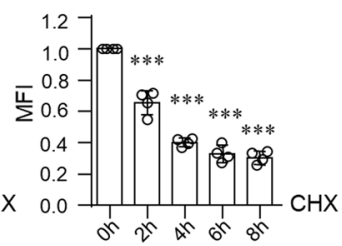

Figure 2. The zRAG2 protein is unstable compared to the mRAG2 protein at $37^{\circ} \mathrm{C}$. (A) Both zRAG2 and mRAG2 had the similar mRNA expression. The mRNA expression levels were normalized to $\beta$-actin expression. (B) The zRAG2 protein showed a lower expression level than the mRAG2 protein. $\beta$-actin served as a loading control for western blot analysis. (C-E) and (F-H) The zRAG2 protein showed an expression level similar to that of the mRAG2 protein, but its MFI was lower than that of mRAG2. zRAG2-GFP fusion protein and mRAG2-GFP fusion protein were introduced into NIH3T3 cells (C-E) or RAG2-deficient pro-B cells (F-H) by the retrovirus-mediated gene transfer method. After $36 \mathrm{~h}$, GFP expression and intensity were analyzed by FACS. (I-L) The zRAG2 level was sensitive to proteasome degradation. RAG2-deficient pro-B cells were treated with CHX for 8 hours. GFP intensity was analyzed by FACS. (I,J) The GFP\% of mRAG2 and zRAG2 was shown; $(\mathbf{K}, \mathbf{L})$ The MFI of mRAG2 and zRAG2 was shown. The error bars indicate the SDs. The data are presented as the mean \pm standard deviation. ${ }^{*} \mathrm{P}<0.05, * * \mathrm{P}<0.01$ and ${ }^{* * *} \mathrm{P}<0.001$ by Student's $\mathrm{t}$ test; N.S.: no significance.

similar observations regarding zRAG2 protein stability (Fig. 3D-F) and recombination efficiency were also made in RAG2-deficient pro-B cells at $28^{\circ} \mathrm{C}$ (Fig. 3J). These results suggested that the protein stability and recombination efficiency of zRAG2 displayed the similar to those of mRAG2 at $28^{\circ} \mathrm{C}$.

The RAG2 protein consists of Kelch (residues 1 350), Hinge (residues 360-408), PHD (residues 414-487) and C-terminal domain (residues $488-527$ or $488-530)^{3,30-32}$. Next, we wondered which domain contributed to the zRAG2 protein instability at $37^{\circ} \mathrm{C}$. We substituted the mRAG2 domain for the corresponding zRAG2 domains to form zRAG2-MK, zRAG2-MH, zRAG2-MP and zRAG2-MC (MK, mouse Kelch; MH, mouse hinge; MP, mouse PHD; and MC, mouse C-terminus) to investigate (Fig. 3K). The CHX chase experiment results showed that the Kelch domain of mRAG2 could improve the MFI level of zRAG2 protein to an equal amount of mRAG2 while other domains including the Hinge, PHD and C-terminus had few improved effects on its stability (Fig. 3L,M). These experiments indicated that the Kelch domain of zRAG2 mediated its instability and that the Kelch domain of mRAG2 could attenuate this instability.

The $\mathrm{V}(\mathrm{D}) \mathrm{J}$ recombination of $\operatorname{Rag} 2^{\mathrm{KI} / \mathrm{KI}}$ mice is severely impaired. To investigate what the characteristics of mice would have been if zRAG2 had not evolved, we constructed a $R a g 2^{\mathrm{KI} / \mathrm{KI}}$ murine model, in which zRAG2 was substituted for mRAG2, via a homologous recombination method in ES cells (Fig. S5A-D) ${ }^{33}$. The $\mathrm{V}(\mathrm{D}) \mathrm{J}$ recombination efficiency of $\mathrm{Rag} 2^{\mathrm{KI} / \mathrm{KI}}$ mice was severely attenuated compared to that of $R a g 2^{+/+}$mice 
A

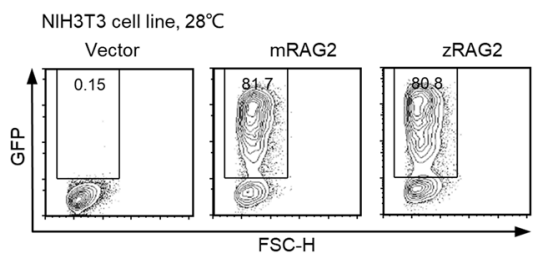

D

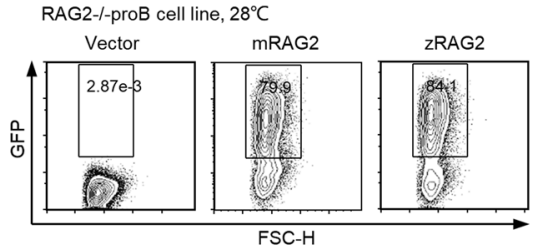

B

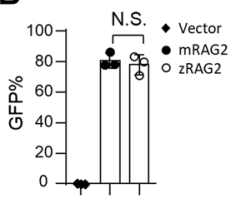

C

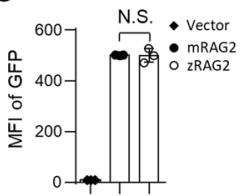

E

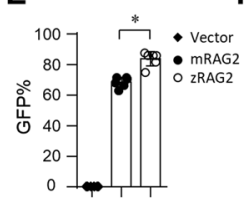

$\mathbf{F}$

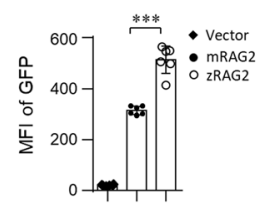

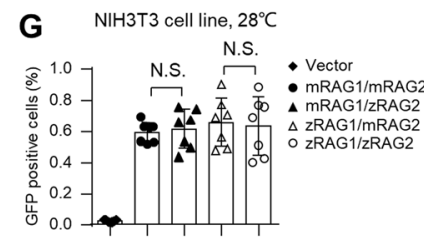

H

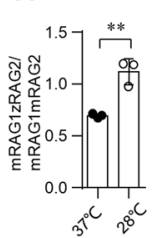

I J

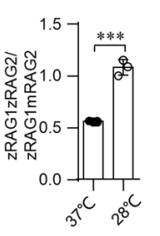

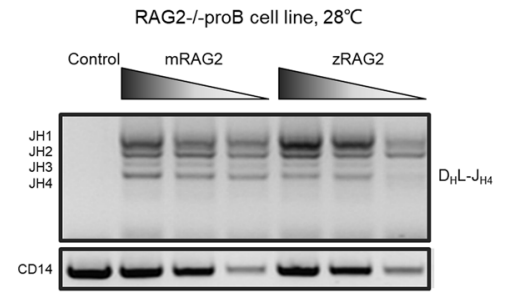

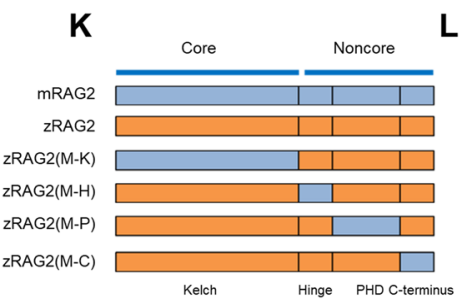

$\mathbf{L}$
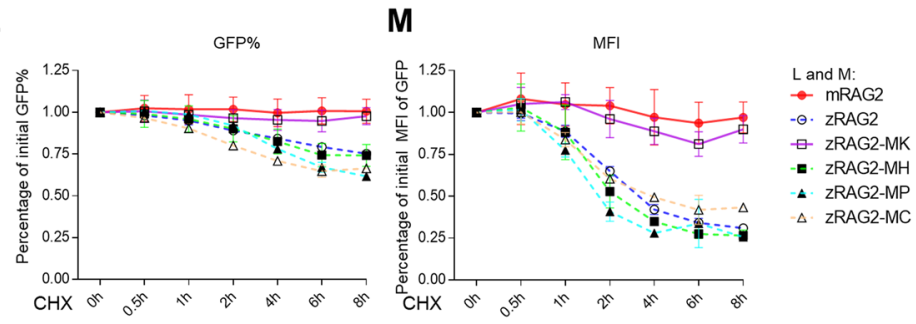

Figure 3. The protein stability and recombination efficiency of zRAG2 are similar to those of mRAG2 at $28^{\circ} \mathrm{C}$. (A-F) The zRAG2 protein showed an expression level similar to that of the mRAG2 protein, and its MFI was also similar to that of mRAG2 or even higher at $28^{\circ} \mathrm{C}$. zRAG2-GFP fusion protein and mRAG2-GFP fusion protein were introduced into NIH3T3 cells (A-C) or RAG2-deficient pro-B cells (D-F) by the retrovirusmediated gene transfer method. The cells were first incubated for $36 \mathrm{~h}$ at $37^{\circ} \mathrm{C}$, and they were transferred to $28^{\circ} \mathrm{C}$ after this time. After $48 \mathrm{~h}$ at $28^{\circ} \mathrm{C}$, GFP expression and intensity were analyzed by FACS. (G) NIH3T3 cells were transfected with pCJGFP using Lipo6000 transfection reagent. The GFP level was measured by flow cytometry to assess the recombination efficiency. The percentages of GFP-positive cells were shown (the means \pm SDs were calculated from triplicate experiments). (H,I) The RAG1zRAG2/mRAG1mRAG2 and zRAG1zRAG2/zRAG1mRAG2 ratios were shown. (J) PCR analyses of the indicated $\mathrm{D}_{\mathrm{H}} \mathrm{J}_{\mathrm{H}}$ family rearrangements in RAG2-deficient pro-B cells at $28^{\circ} \mathrm{C}$. Input control: CD14 (bottom). PCR amplification was performed with fivefold serial dilutions of genomic DNA. The results are typical of three experiments. Bands related to rearrangements of various $\mathrm{J}_{\mathrm{H}}$ segments are indicated on the left. (K-M) Different mouse RAG2 domains were substituted for the corresponding zRAG2 domains. GFP\% (L) and MFI (M) are shown from $0 \mathrm{~h}$ to $8 \mathrm{~h}$ after treatment with the $20 \mu \mathrm{g} / \mathrm{ml} \mathrm{CHX}$. MK, mouse Kelch; $\mathrm{MH}$, mouse hinge; MP, mouse PHD; MC, mouse $\mathrm{C}$-terminus. The error bars indicate the SDs. The data are presented as the mean \pm standard deviation. $* \mathrm{P}<0.05, * * \mathrm{P}<0.01$ and $* * * \mathrm{P}<0.001$ by Student's t test; N.S.: no significance.

(Fig. 4A,B), which was consistent with our observations in NIH3T3 and RAG2-deficient cells (Fig. 1A,B,J). TCR $\beta$ intracellular staining further verified the extremely decreased V(D)J recombination efficiency of Rag2 $2^{\mathrm{KI} / \mathrm{KI}}$ mice (Fig. 4C). Additionally, analysis of the sequences of $\mathrm{D}_{\beta}-\mathrm{J}_{\beta}$ recombination products indicated that the signal joints of $\mathrm{D}_{\beta 1}-\mathrm{J}_{\beta 1.1}$ and $\mathrm{D}_{\delta} 2-\mathrm{J}_{\delta} 1$ recombination from the Rag $2^{\mathrm{KI} / \mathrm{KI}}$ mice were similar to those from wild-type mice (Fig. S6A,B). However, the impaired accuracy of $\mathrm{V}(\mathrm{D}) \mathrm{J}$ recombination in the Rag $2^{\mathrm{KI} / \mathrm{KI}}$ mice was detected in $\mathrm{D}_{\beta 2}-\mathrm{J}_{\beta 2.1}$ recombination (Fig. S6C). These results suggested that Rag $2^{\mathrm{KI} / \mathrm{KI}}$ mice had impaired V(D)J recombination efficiency and accuracy. Consistently, Rag $2^{\mathrm{KI} / \mathrm{KI}}$ mice showed severe combined immunodeficiency phenotypes because of impaired V(D)J recombination (Fig. 4D-G). T cell development of Rag2 ${ }^{\mathrm{KI} / \mathrm{KI}}$ mice was blocked in the early stages like $\mathrm{Rag}^{-/-}$mice which were blocked at the DN3 stage (CD4 ${ }^{-} \mathrm{CD} 8^{-}$double-negative stage) (Fig. 4D). The percentage of DP cells $\left(\mathrm{CD} 4^{+} \mathrm{CD}^{+}\right.$double positive cells) of the thymus was severely diminished (from $84.8 \%$ in wild-type mice to $0.9 \%$ in $\operatorname{Rag}^{\mathrm{KI} / \mathrm{KI}}$ mice) (Fig. $4 \mathrm{E}$ ). Similar phenomena were also observed in $\mathrm{B}$ cells; the $\mathrm{B}$ cell development of Rag $2^{\mathrm{KI} / \mathrm{KI}}$ mice was blocked at the pro-B stage, and the percentage of pre- $\mathrm{B}$ cells in bone marrow was also severely diminished (from $22.6 \%$ in wild-type mice to $0.3 \%$ in Rag $2^{\mathrm{KI} / \mathrm{KI}}$ mice) (Fig. $4 \mathrm{~F}$ ). The percentage of mature B cells was dramatically diminished from $9.3 \%$ in wild-type mice to $0.4 \%$ in $\operatorname{Rag} 2^{\mathrm{KI} /}$ ${ }_{\mathrm{KI}}$ mice (Fig. 4G). These results indicated that the evolution of ectotherm RAG2 is required for adapting to the 
A

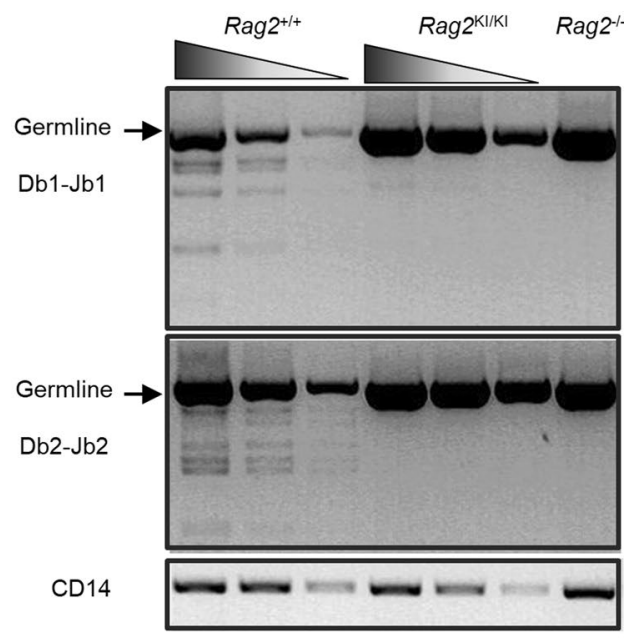

D

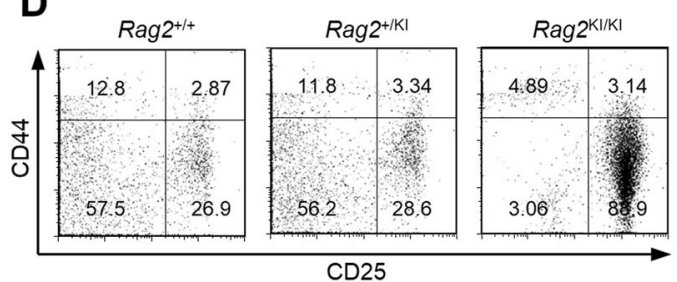

E

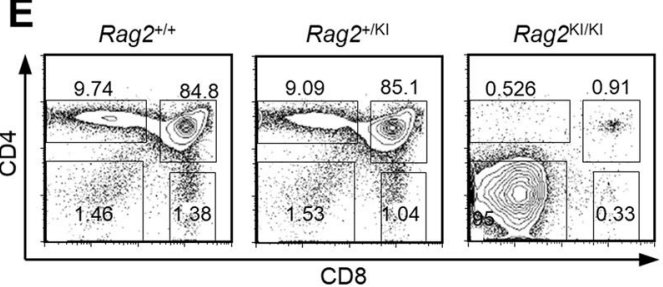

B
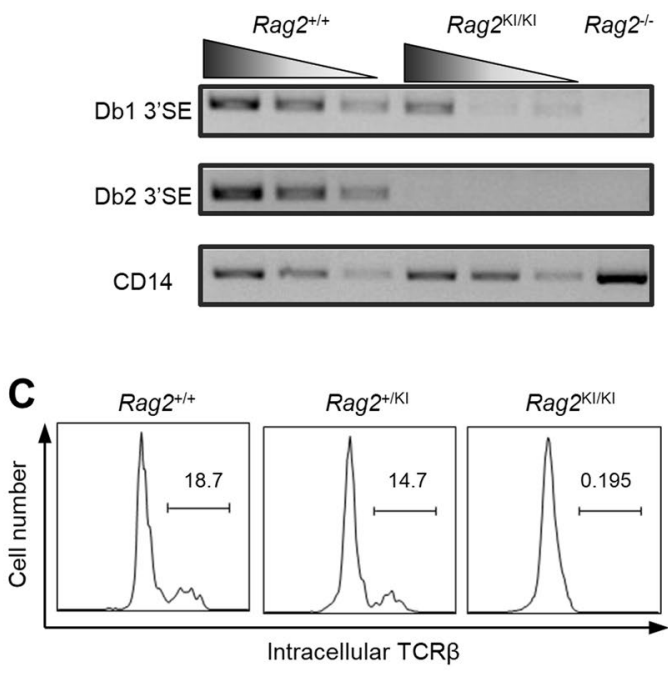

F

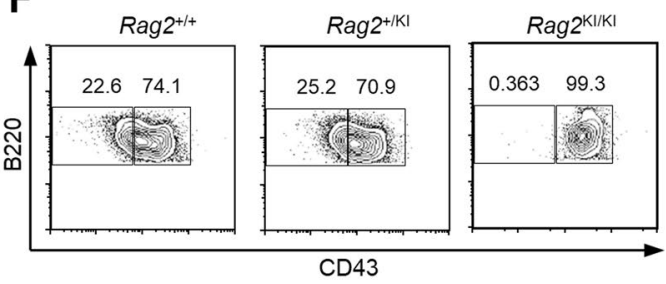

G

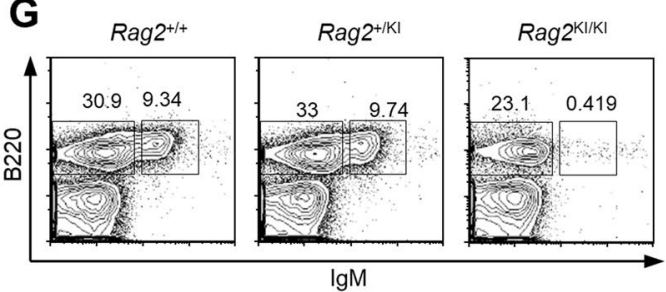

Figure 4. The $\mathrm{V}(\mathrm{D}) \mathrm{J}$ recombination of $\mathrm{Rag} 2^{\mathrm{KI} / \mathrm{KI}}$ mice is severely impaired. Flow cytometric analysis of $\mathrm{T}$ and $\mathrm{B}$ cell development in Rag2 $2^{+/+}, \operatorname{Rag} 2^{+/ \mathrm{KI}}$ and $\operatorname{Rag} 2^{\mathrm{KI} / \mathrm{KI}}$ mice. $(\mathbf{A}, \mathbf{B}) \mathrm{TCR} \beta$ rearrangement was found to be decreased via semiquantitative PCR, which was used to detect $\mathrm{D}_{\beta}-\mathrm{J}_{\beta}$ rearrangement in $\mathrm{DN} 3$ thymocytes $\left(\mathrm{CD} 4^{-} \mathrm{CD} 8^{-} \mathrm{CD} 44^{-} \mathrm{CD} 25^{+}\right.$population) sorted from Rag2 $2^{\mathrm{KI} / \mathrm{KI}}$ mice, their WT littermates and RAG2 ${ }^{-1-}$ mice. Input control: CD14 (bottom). PCR amplification was performed with fivefold serial dilutions of genomic DNA. The results are representative of three independent experiments. (C) The intracellular TCR $\beta$ expression level in $R a g 2^{\mathrm{KI} / \mathrm{KI}}$ mice was largely diminished compared to that in $\mathrm{Rag} 2^{+/+}$or $\mathrm{Rag} 2^{\mathrm{KI} /+}$ mice. The TCR $\beta$ expression level was measured by flow cytometry. (D-G) The surface expression of CD4, CD8, B220, IgM, and CD43 in Rag2 ${ }^{\mathrm{KI} / \mathrm{KI}}$ mice (mice with two zRAG2 knock-in alleles) and Rag $2^{+/+}$mice (WT littermates) was analyzed by flow cytometry. (D) CD44 and CD25 surface expression in DN cells of the thymus. (E) CD4 and CD8 surface expression on thymocytes. (F) $\operatorname{IgM}^{-}$bone marrow cells were analyzed for surface expression of B220 and CD43. (G) The B220 and IgM surface expression on bone marrow cells. The results are representative of three independent experiments.

elevated body temperature of the higher endothermic vertebrates. Without this adaptation, endothermic jawed vertebrates would have an attenuated $\mathrm{V}(\mathrm{D}) \mathrm{J}$ recombination efficiency and lead to severe immunodeficiency.

Rag2 ${ }^{\mathrm{KI} / \mathrm{KI}}$ mice develop severe cachexia syndromes. To our surprise, $R a g 2^{\mathrm{K} / \mathrm{KI}}$ mice unexpectedly not just had a severely impaired $\mathrm{V}(\mathrm{D}) \mathrm{J}$ recombination efficiency, but developed severe cachexia syndromes that were characterized by smaller body size (Fig. 5A), skeletal muscle wasting (Fig. 5B), significant weight loss (Fig. 5C), systematic immune infiltration (Fig. 5D,E). More interestingly, Rag $2^{\mathrm{KI} / \mathrm{KI}}$ mice had a shortened lifespan even than Rag2 $2^{-1-}$ mice (Fig. 5F).

Chronic inflammation is one of the major drivers of cachexia ${ }^{34,35}$. It have been identified that four pro-inflammatory cytokines including tumor necrosis factor alpha (TNF- $\alpha$, initially named cachectin), interferon- $\gamma$ (IFN- $\gamma$ ), interleukin-6 (IL-6) and interleukin-1 (IL-1) contributed to the cachexia syndrome ${ }^{34,36}$. In the four cachexia cytokines, T cell expressed IFN- $\gamma$, TNF- $\alpha$ and IL- $6^{37-41}$. Interestingly, we found that CD4 


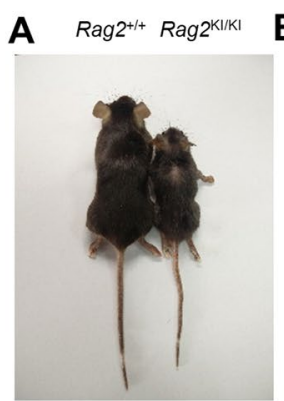

60 Days

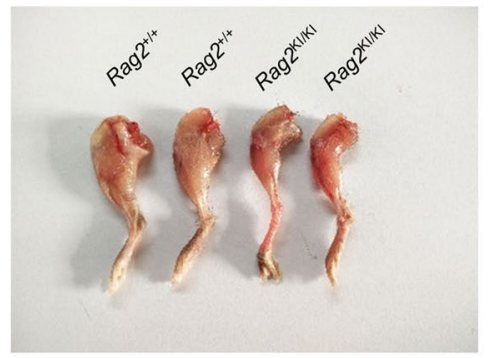

60 Days
C

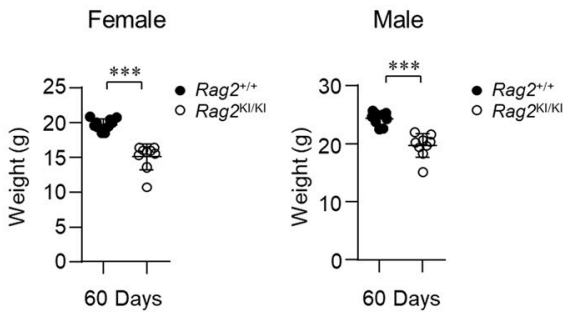

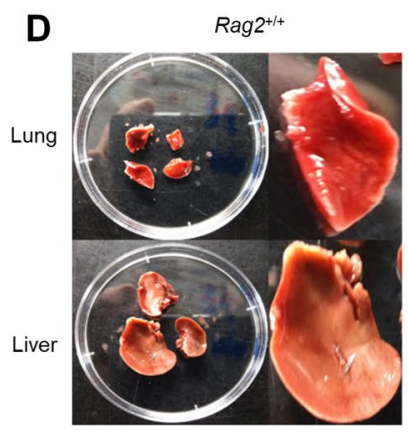

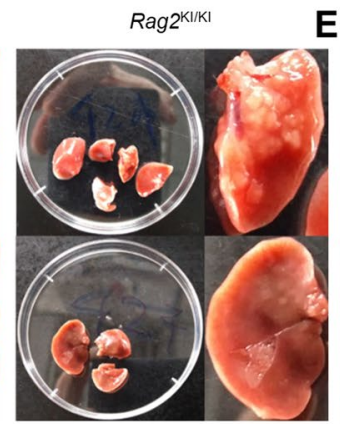

E
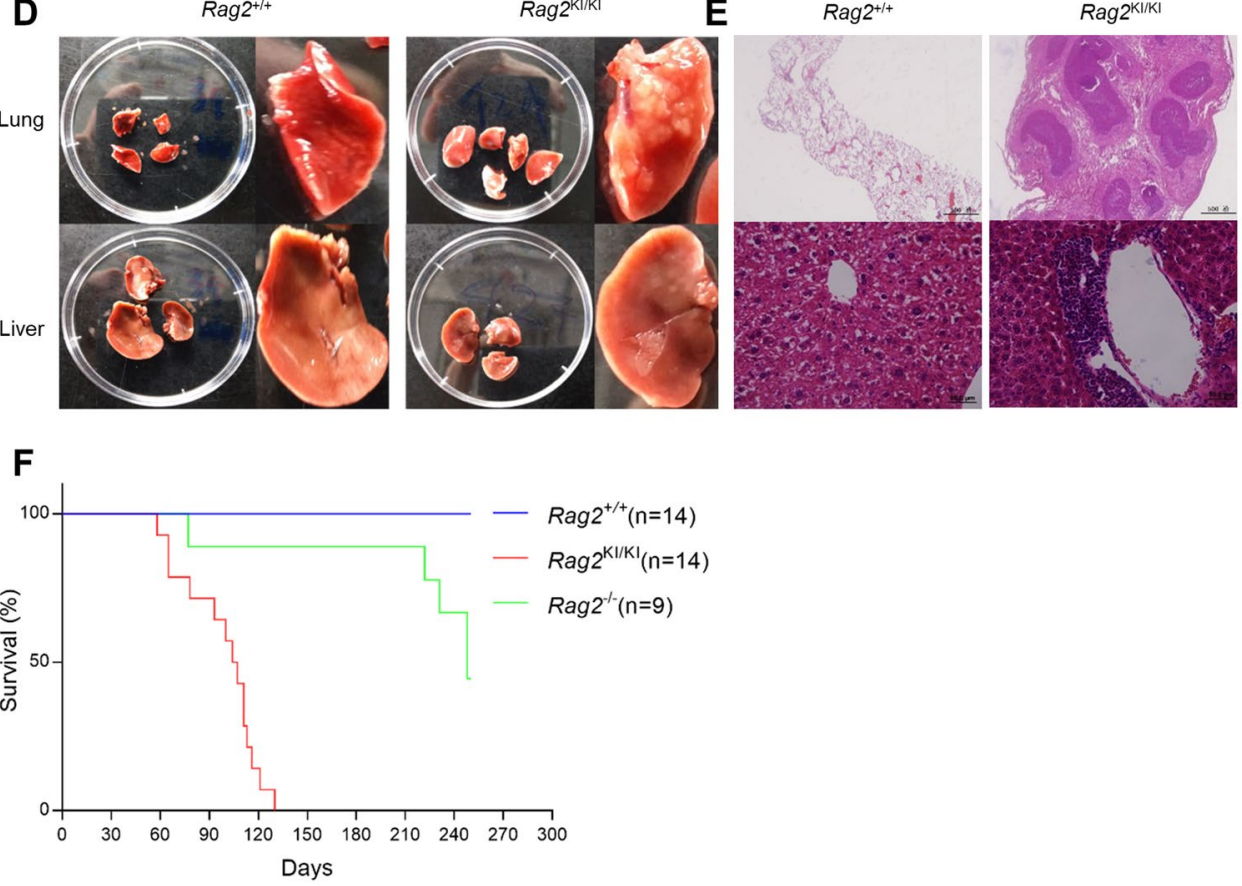

Figure 5. $\operatorname{Rag} 2^{\mathrm{KI} / \mathrm{KI}}$ mice develop severe cachexia syndromes. (A) Representative photographs of 2 months old Rag $2^{\mathrm{KI} / \mathrm{KI}}$ mice and wild-type Rag2 ${ }^{+/+}$littermates. (B) Skin was stripped from the hind limbs of 60 days old mice for gross comparisons of muscle mass. (C) Total body weight of 2 months old Rag2 $2^{+/+}$mice $(\mathrm{n}=9) \operatorname{Rag} 2^{\mathrm{KI} / \mathrm{KI}}$ mice $(n=9)$. (D) Representative photographs of lungs and livers from $2-5$ months old $R a g 2^{\mathrm{KI} / \mathrm{KI}}$ mice and wildtype Rag $2^{+/+}$littermates. (E) Representative H\&E staining of lung and liver sections at $2-5$ months old Rag2 $2^{\mathrm{KI} / \mathrm{KI}}$

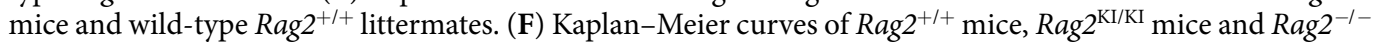
mice (Rag2 $2^{+/+}$mice, $\mathrm{n}=14 ; \operatorname{Rag}^{\mathrm{KI} / \mathrm{KI}}$ mice, $\mathrm{n}=14 ;$ Rag2 $^{-/-}$mice, $\mathrm{n}=9$ ). Chi square log-rank test was used for statistical analysis. The results are representative of three independent experiments. The error bars indicate the SDs. The data are presented as the mean \pm standard deviation. $* \mathrm{P}<0.05$, ** $\mathrm{P}<0.01$ and $* * * \mathrm{P}<0.001$ by Student's t test.

$\mathrm{T}$ cells and CD8 T cells from Rag $2^{\mathrm{KI} / \mathrm{KI}}$ mice were highly activated characterized by the increased CD69high ${ }^{\text {cells }}$ (Fig. S7A,B) and CD44 ${ }^{\text {high }}$ CD62 $2^{\text {low }}$ cells (Fig. S7C,D) in the lymph nodes, spleen, lung, liver and brain. To our surprise, we found that the absolute cell numbers of total immune cells from peripheral immune organs of Rag $2^{\mathrm{KI} /}$ ${ }_{\mathrm{KI}}$ mice was dramatically decreased while the cell numbers of total immune cells from non-immune organs of Rag $2^{\mathrm{KI} / \mathrm{KI}}$ mice was no less (Fig. 6A). Further research showed that CD4 T cells were markedly increased (Fig. 6B) and they ectopically produced different cachexia cytokines in different non-immune organs (Fig. 6D-F and Fig. S8A-C). In the lung, IFN- $\gamma$ and TNF- $\alpha$ produced by CD $4 \mathrm{~T}$ cells of $R a g 2^{\mathrm{KI} / \mathrm{KI}}$ mice were increased compared to Rag $2^{+/+}$mice (Fig. 6D and Fig. S8A). In the liver, IFN- $\gamma$, TNF- $\alpha$ and IL-6 produced by CD4 T cells of Rag2 $2^{\mathrm{KI} /}$

${ }_{\mathrm{KI}}$ mice were increased compared to Rag2 ${ }^{+/+}$mice (Fig. 6E and Fig. S8B). In the brain, TNF- $\alpha$ produced by CD 4 $\mathrm{T}$ cells of $\mathrm{Rag} 2^{\mathrm{KI} / \mathrm{KI}}$ mice were specially increased compared to Rag $2^{+/+}$mice (Fig. $6 \mathrm{~F}$ and Fig. S8C). There was no increase found in CD8 T cells from the three non-immune organs (lung, liver and brain) of Rag $2^{\mathrm{KI} / \mathrm{KI}} \mathrm{mice}$ compared to Rag2 $2^{+/+}$mice (Fig. 6C), and the absolute numbers of CD8 T cells that produced cachexia cytokines of Rag $2^{\mathrm{KI} / \mathrm{KI}}$ mice were also no increase compared to Rag $2^{+/+}$mice (Fig. 6G-I) in spite of the dramatically increased percentage of these cachexia cytokines produced by CD8 T cells. (Fig. S8D-F). Our results identified that Rag $2^{\mathrm{KI} /}$ ${ }_{\mathrm{KI}}$ mice developed severe cachexia syndromes from individual phenotype to molecular and cell levels. These results suggested that the lower ectothermic vertebrate RAG2 might further evolve to adapt to the elevated body 
A

Total immune cells

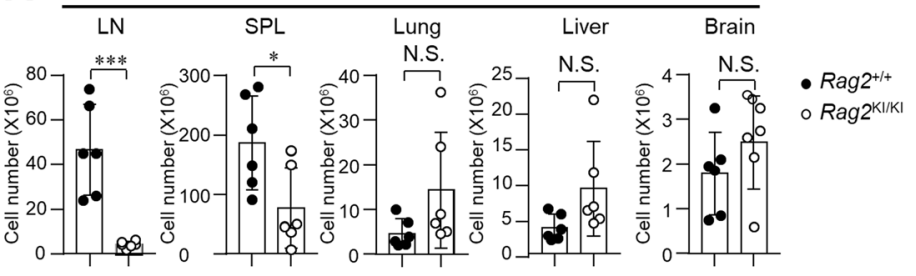

B CD4 T cells
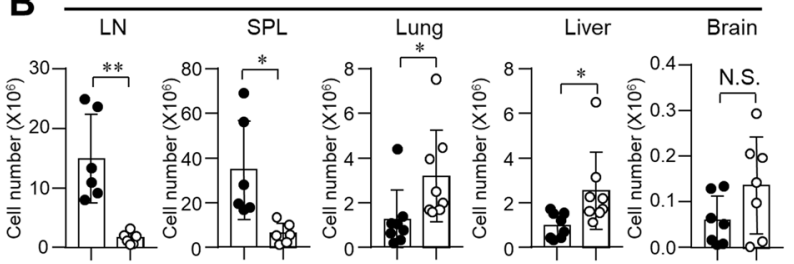

- $R a g 2^{+/+}$

C

CD8 T cells

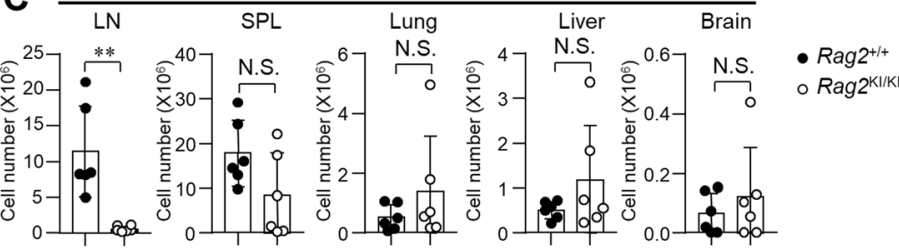

D

CD4 T cells (Lung)

G

CD8 T cells (Lung)

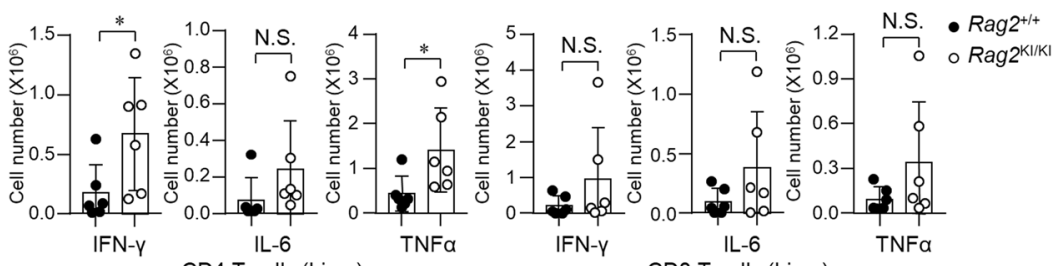

E CD4T cells (Liver) $\mathbf{H}$

CD8 T cells (Liver)
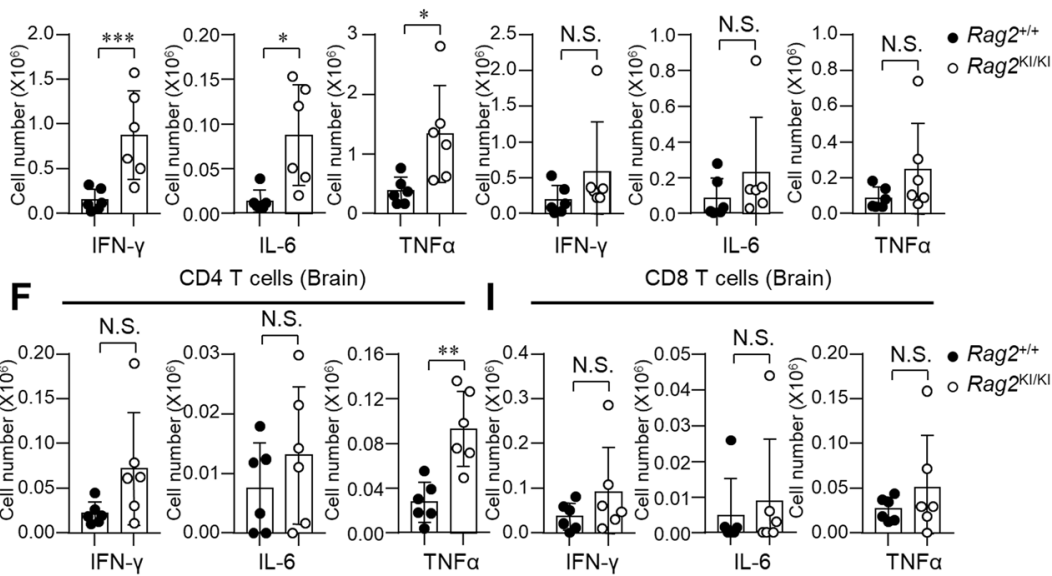

Figure 6. T cells that produced cachexia cytokines of Rag2 ${ }^{\mathrm{KI} / \mathrm{KI}}$ mice are disordered. (A) Total immune cells of

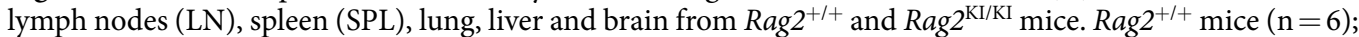
$\operatorname{Rag} 2^{\mathrm{KI} / \mathrm{KI}}$ mice $(\mathrm{n}=6)$. (B) The absolute CD4 T cells of $\mathrm{LN}$, SPL, lung, liver and brain from Rag2 $2^{+/+}$and $R a g 2^{\mathrm{KI} /}$ ${ }^{\mathrm{KI}}$ mice. Rag2 ${ }^{+/+}$mice $(\mathrm{n}=6)$; Rag $2^{\mathrm{KI} / \mathrm{KI}}$ mice $(\mathrm{n}=6)$. $(\mathrm{D}-\mathrm{F})$ The disorder of IFN- $\gamma$, IL-6 and TNF $\alpha$ of CD4 T

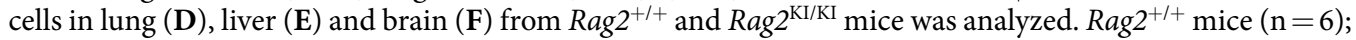

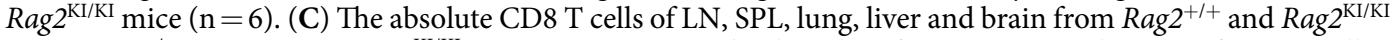
mice. Rag $2^{+/+}$mice $(\mathrm{n}=6) ; \operatorname{Rag} 2^{\mathrm{KI} / \mathrm{KI}}$ mice $(\mathrm{n}=6)$. $(\mathbf{G}-\mathbf{I})$ The disorder of IFN- $\gamma$, IL-6 and TNF $\alpha$ of CD8 T cells in lung $(\mathbf{G})$, liver $(\mathbf{H})$ and brain $(\mathbf{I})$ from $R a g 2^{+/+}$and $R a g 2^{\mathrm{KI} / \mathrm{KI}}$ mice was analyzed. $R a g 2^{+/+}$mice $(\mathrm{n}=6)$; $R a g 2^{\mathrm{KI} /}$ ${ }_{\mathrm{KI}}$ mice $(\mathrm{n}=6)$. All cytokines were detected by flow cytometric analysis after in vitro stimulation with PMA (phorbol 12-myristate 13-acetate) and ionomycin in the presence of brefeldin A for $4 \mathrm{~h}$. The error bars indicate the SDs. The data are presented as the mean \pm standard deviation. $* \mathrm{P}<0.05$, $* * \mathrm{P}<0.01$ and $* * * \mathrm{P}<0.001$ by Student's t test; N.S.: no significance. 
temperature of the higher endothermic vertebrates in the evolution of jawed vertebrates. Otherwise, endothermic jawed vertebrates would have not only had weaker recombination efficiency and immunodeficiency but also developed severe cachexia syndromes.

\section{Discussion}

Although the origination of RAG in invertebrates has been extensively studied, the evolution of RAG in jawed vertebrates remains largely unknown. Our findings suggest that the evolution of zebrafish RAG2 protein is required for adapting to the elevated body temperature of the higher endothermic vertebrates. Importantly, zRAG2, but not $z R A G 1$, which possesses endonuclease activity, is responsible for the reduced recombination efficiency of zRAG compared to mRAG at $37^{\circ} \mathrm{C}$. If the lower ectotherm RAG2 such as zRAG2 did not evolve, endothermic jawed vertebrates such as mice would have not only had weaker recombination efficiency and immunodeficiency but also developed severe cachexia syndromes.

Protein adaptation is essential for organismal evolution ${ }^{42,43}$. Allosteric regulation is a general and widespread evolutionary adaptation mechanism that fine-tunes biological function without changing fundamental structures $^{43-45}$. RAG recombinase as an allosteric protein is composed of a heterotetrameric complex including two subunits each of RAG1 and RAG2 $2^{3,30,31}$. RAG1, as an endonuclease, plays direct roles in both RSS binding and DNA cleavage, and is the actual workhorse in the process of $\mathrm{V}(\mathrm{D}) \mathrm{J}$ recombination ${ }^{3,10,46,47}$. In contrast, RAG2 is a vital allosteric factor whose principal function seems to interact with RAG1 and activate the enzymatic activity of RAG1 endonuclease $\mathrm{e}^{3,47,48}$. Allosteric activators and cofactors gain their complementary regulatory properties simultaneously for specific functions, and the cofactors offer an advantage under evolutionary selective pressure ${ }^{43,49,50}$. This strategy for evolution is called conditional neutrality ${ }^{43}$. The mutation of cofactors may be regarded as a better strategy for adaption under evolutionary pressure than the mutation activator ${ }^{43}$. Thus, in the machinery of allostery, RAG1 can be regarded as the activator whereas RAG2 can be referred to as the cofactor. It has been reported that RAG2 can alter the conformation of RAG1 and stabilize interactions of RAG1 with the heptamer ${ }^{47}$. Similar to other allosteric proteins, RAG2 may have adapted during evolution via mutation. Importantly, the RAG2 Kelch domain is located at the interface of binding between RAG1 and RAG2. Mutations in the RAG2 Kelch domain block initiation of $\mathrm{V}(\mathrm{D}) \mathrm{J}$ recombination and lead to severe combined immunodeficiency (SCID) or Omenn syndrome (OS) immunodeficiency ${ }^{51,52}$. Hence, RAG2 mutations, particularly those in the Kelch domain, can likely be regarded as candidates driving RAG adaptation during the evolution of jawed vertebrates from ectotherms to endotherms without abrogating the rearrangement function of RAG1, consistent with the property of conditional neutrality.

Zebrafish mainly live in freshwater streams and rivers of northeastern India. Due to monsoon climate in their native geographic range, zebrafish have adapted to a broad range of temperatures, including temperatures from $12^{\circ} \mathrm{C}$ to $39^{\circ} \mathrm{C}^{53-55}$. Our results suggest that zRAG1/mRAG2 performs a fiercer recombination than mRAG1/mRAG2 and zRAG1/zRAG2. It has been reported that RAG endonuclease is a potent threat to genome stability because the lymphocyte genome owns thousands of RSS sites that can be recognized and bound by RAG ${ }^{25}$. Epistasis is the primary factor in molecular evolution ${ }^{56-59}$. For keeping constant metabolic capacity, many ectothermic vertebrate enzyme activities are upregulated or downregulated in their fluctuating thermal environments ${ }^{60}$. Given that zRAG can well perform the $\mathrm{V}(\mathrm{D}) \mathrm{J}$ recombination at low environmental temperature $28^{\circ} \mathrm{C}$, we speculate that zebrafish may constrain zRAG1 endonuclease hyperactivity at high environmental temperature $37^{\circ} \mathrm{C}$ via zRAG2 stability-mediated antagonistic epistasis to constrain the potential threat of RAG1 endonuclease for the genome stability.

The process of evolution from ectotherms to endotherms was one of the most prominent events in vertebrate evolution $^{60}$. These dramatic transitions in the organisms themselves brought many challenges to the ectotherms that would ultimately achieve high and stable body temperatures of $37-42^{\circ} \mathrm{C}^{61}$. Temperature profoundly affects every physiological function (e.g., metabolism, locomotion, and fecundity) ${ }^{62,63}$. However, details of the evolution of the adaptive immune system in this progress, especially at the molecular level, remain unclear. Our study suggests that the core component RAG of the adaptive immune system, especially RAG2, is indeed different between ectotherms and endotherms. It has been reported that RAG may have originated in the invertebrate amphioxus ${ }^{8,9}$. However, the amphioxus such as Asymmetron lucayanum lives in seawater with annual temperatures ranging from $23^{\circ} \mathrm{C}$ to $29^{\circ} \mathrm{C}$ (monthly means) which are lower than $37^{\circ} \mathrm{C}^{64}$. It is reasonable to assume that RAG had no necessity or pressure to adapt to high temperatures in the beginning. Considering this assumption, we propose that the adaptive immune system of jawed vertebrates represented by RAG2 might have further evolved to adapt to a high and stable $\mathrm{Tb}$ during the evolution from ectotherms to endotherms.

It has been reported that the mutations in the positions V8, F62, T77, C446 and C478 from RAG2 would lead to structural destabilization of the RAG2 protein or RAG1/2 complex ${ }^{65-67}$. We compared the amino acid sequence of endotherm RAG2 and ectotherm RAG2 proteins. We found that V8 and T77 were not conserved between ectotherms and endotherms while the C446 and C478Y from RAG2 were conserved and F62 except omRAG2 was conserved between ectotherms and endotherms. Therefore, the phenotype of the knock-in mouse may be somewhat because of the instability of zRAG2/mRAG1 protein complex. More importantly, the cachexia syndromes were not found in our previous study on $\operatorname{Rag} 2^{\mathrm{C} 478 \mathrm{Y}}$ mice that the $\mathrm{V}(\mathrm{D}) \mathrm{J}$ recombination efficiency of $R a g 2^{\mathrm{C} 478 \mathrm{Y}}$ protein was also dramatically attenuated because of its instability at $37^{\circ} \mathrm{C}^{67}$. Given that zRAG2 is a genuine existed RAG2, not a mRAG2 mutant, we speculate that zRAG2 may have other functions besides the V(D)J recombination at $37^{\circ} \mathrm{C}$ that do not function at $28^{\circ} \mathrm{C}$ considering the products of $\mathrm{V}(\mathrm{D}) \mathrm{J}$ recombination mediated by $z$ RAG 2 . Specially, why zRAG2 results in the severe cachexia syndromes of Rag2 ${ }^{\mathrm{KI} / \mathrm{KI}}$ mice remains further research.

\section{Materials and Methods}

Mice. PGK-Cre transgenic mice were kindly provided by Dr. X. Wu (Fudan University, Shanghai, China). To generate DaR2 knock-in mice, targeting vectors containing DaR2, a diphtheria toxin A (DTA) negative selection cassette, and a PGK-neo cassette were used for the electroporation of embryonic stem (ES) cells. The targeted ES cell clones were kindly provided by the Stem Cell Bank, Chinese Academy of Sciences. These clones were 
microinjected into C57BL/6 blastocysts using a PiezoXpert (Eppendorf) to generate chimeric mice. Male chimeras were bred to $\mathrm{C} 57 \mathrm{BL} / 6$ female mice, and the heterozygous progeny were crossed with PGK-Cre mice to remove the floxed PGK-Neo cassette. All mice were maintained in specific pathogen-free facilities. All mice were genotyped using PCR analysis before experimentation, and all animal experiments were approved by the Institutional Animal Care and Use Committee of the Shanghai Institutes for Biological Sciences of the Chinese Academy of Sciences. We confirmed that all experiments were performed in accordance with relevant guidelines and regulations.

Plasmids. pEBG-RAG1 (mouse) and pEBG-RAG2 (mouse), which have been previously described, were used for recombination assays in NIH3T3 and HEK-293T cells. DNAs encoding the zRAG2, mRAG2, omRAG2 and onRAG2 genes were synthesized by Sangon Biotech. Then, the synthesized RAG2 genes were cloned into pEBG and pMX plasmid vectors. For RAG2 or RAG1 protein stability assays in NIH3T3 and RAG1 $1^{-1-}$ or $\mathrm{RAG}^{-1-}$ pro-B cells, pMX-GFP-mRAG2 and pMX-GFP-mRAG1 vectors were used; these vectors have been previously described ${ }^{67,68}$.

Cell culture and transfection. Abelson-transformed Rag2 $2^{-1-}$ tg.bcl2 pro- B cells were maintained in complete RPMI 1640 medium (Hyclone). Retroviral transfection was performed as described previously. Briefly, Plat-E cells were transfected with $2.5 \mu \mathrm{g}$ of GFP-tagged RAG2 in a pMX-flag vector. The supernatant was collected $48 \mathrm{~h}$ post transfection, polybrene was added at a concentration of $5 \mu \mathrm{g} / \mathrm{mL}$, and Rag $2^{-l-}$ pro-B cells were resuspended at 0.6 million cells/mL. The transduction period lasted for $12 \mathrm{~h}$, and the cells were analyzed after $48 \mathrm{~h}$ by flow cytometry.

Antibodies and reagents. Anti-CD4 (RM4-5), anti-CD8a (53-6.7), anti-CD44 (IM-7), anti-CD25 (PC61), anti-Cd11b (M1/70), anti-TER-119 (TER-119), anti-IgM (R6-60.2), anti-TCR3 (H57-597), anti-CD62L (MEL14), anti-CD69 (H1.2F3) anti-IL-6 (MP5-20F3) and TNF- $\alpha$ (MP6-XT22) were purchased from BD Pharmingen. Anti-B220 (RA3-6B2) and anti-CD3 (145-2C11), anti-IFN- $\gamma$ (XMG1.2) were purchased from BioLegend. Anti-CD43 (GL3) was purchased from eBioscience (eBioR2/60). PMA and ionomycin were purchased from Merck. Cycloheximide was purchased from Sigma. MG-132 was obtained from Merck. Taq Plus Master Mix for genotyping was from Vazyme Biotech. Chloroquine was obtained from MCE. Collagenase IV was obtained from Sigma. DNase I was obtained from Shanghai Sanjie.

Cell preparation, staining, and purification. Single cell from thymus, lymph nodes, spleen, liver, lung and brain suspensions were prepared and surface-stained as described previously ${ }^{9,69-71}$. Briefly, the thymus and lymph nodes were dissected from mice, and single-cell suspensions were prepared by gently teasing the tissue with forceps and then passing it through nylon filters. The liver and brain were dissected from the body, cut into pieces, minced in PBS buffer and thereafter filtered through a $40 \mu \mathrm{m}$ cell strainer. The lungs were cut into pieces and incubated with shaking $\left(200 \mathrm{rpm}\right.$ ) at $37^{\circ} \mathrm{C}$ for $1.5 \mathrm{~h}$ in RPMI medium (Gibco) containing 5\% FBS (Gibco), $160 \mu \mathrm{g} / \mathrm{ml}$ collagenase IV (Sigma) and $0.2 \mu \mathrm{g} / \mathrm{ml}$ DNase I (Shanghai Sanjie). Leukocytes were isolated from the liver and brain cell suspensions or digested lungs by density fractionation using discontinuous $40-70 \%$ (vol/vol) Percoll (GE Healthcare) gradients. The cells were distributed in $5 \mathrm{~mL}$ polystyrene round-bottom tubes (Corning, Inc.) and stained for $40 \mathrm{~min}$ at $4{ }^{\circ} \mathrm{C}$ with the indicated antibodies. Cell fluorescence was observed using a two-laser FACSCalibur (BD Biosciences), a five-laser BD LSRFortessa (BD Biosciences) and a three-laser CytoFLEX (Beckman) flow cytometers. The data were analyzed with FlowJo software (TreeStar, Inc., Olten, Switzerland). Subsets of thymocytes were sorted using a FACSAria II flow cytometer (BD Biosciences).

Intracellular staining. Intracellular staining was performed as described previously ${ }^{70,71}$. For intracellular staining, cells were stimulated with $50 \mathrm{ng} / \mathrm{ml} \mathrm{PMA} \mathrm{(phorbol} 12$-myristate 13 -acetate), $1 \mu \mathrm{g} / \mathrm{ml}$ inomycin, and $1 \mu \mathrm{g} /$ $\mathrm{ml}$ brefeldin A for $4 \mathrm{~h}$. After $4 \mathrm{~h}$, these cells were fixed with $2 \%$ PFA, permeabilized with Perm cell permeabilization kit (eBiosciences), and stained with antibodies specific to intracellular cytokines. For intracellular staining of TCR $\beta$, cells were fixed with $2 \%$ PFA, permeabilized with Perm cell permeabilization kit (eBiosciences), and stained with antibodies specific to TCR $\beta$.

PCR analysis of Tcrb, Tcrd and IgH recombination products. Genomic DNA was prepared from bone marrow pro-B (B220 IgM $\left.^{-} \mathrm{CD} 43^{\text {high }}\right)$ and DN3 cells $\left(\mathrm{CD} 4^{-} \mathrm{CD} 8^{-} \mathrm{CD} 44^{-} \mathrm{CD} 25^{+}\right)$that were sorted with a FACSAria II (BD Biosciences). For RAG1-deficient or RAG2-deficient pro-B cell lines, the genomic DNA was directly extracted ${ }^{9,68,69}$. Then, fivefold serial dilutions of the genomic DNA ( $200 \mathrm{ng}, 40 \mathrm{ng}$, and $8 \mathrm{ng}$ ) were used to detect TCR $\beta, T C R \gamma \delta$ and IgH recombination by PCR, and CD14 was used as an internal control ${ }^{9,68,69}$. The primers for $\mathrm{D}_{\beta} 1 \mathrm{~J}_{\beta} 1, \mathrm{D}_{\beta} 2 \mathrm{~J}_{\beta} 2, \mathrm{D}_{\delta} 2 \mathrm{~J}_{\delta} 2, \mathrm{D}_{\mathrm{H}} \mathrm{J}_{\mathrm{H}}$ and CD14 were previously described ${ }^{9,26,68,69}$. The following numbers of PCR cycles were used to detect the recombinant products: for $\mathrm{D}_{\beta} 1 \mathrm{~J}_{\beta} 1, \mathrm{D}_{\beta} 2 \mathrm{~J}_{\beta} 2, \mathrm{D}_{\delta} 2 \mathrm{~J}_{\delta} 2$ and $\mathrm{D}_{\mathrm{H}} \mathrm{J}_{\mathrm{H}}$ coding joints, 28 cycles; for CD14, 26 cycles; and for $\mathrm{D}_{\delta} 1 \mathrm{~J}_{\delta} 1 \mathrm{SJs}, 35$ cycles $^{9,26,68,69}$. The PCR cycles for these analyses were as follows: $30 \mathrm{~s}$ at $95^{\circ} \mathrm{C}, 30 \mathrm{~s}$ at $60^{\circ} \mathrm{C}$ and $2.5 \mathrm{~min}, 30 \mathrm{~s}$ at $72^{\circ} \mathrm{C}$. The PCR products were separated on $1.5 \%$ agarose gels and then subjected to TA cloning (TaKaRa). The resulting plasmids were transformed into $E$. coli $\mathrm{DH} 5 \alpha$ cells for sequence analysis.

RNA isolation and quantitative real-time PCR analysis. Total RNA was extracted from FACS-sorted pro-B (B220 $\left.{ }^{+} \mathrm{IgM}^{-} \mathrm{CD} 43^{\text {high }}\right)$ and DN3 cells (CD4 $\left.{ }^{-} \mathrm{CD} 8^{-} \mathrm{CD} 44^{-} \mathrm{CD} 25^{+}\right)$using TRIzol reagent (Invitrogen), and then the RNA was reverse transcribed with a HiScript II Q RT SuperMix for qPCR Kit (Vazyme). Real-time PCR was performed with SYBR Green Realtime PCR Master Mix (Toyobo) on a Bio-Rad CFX96 3.1 PCR system. 
$\beta$-actin was used as an internal control for RT-PCR. The primer pairs for the genes examined were as follows: mRAG2, 5' -CCAGGAGACAATAAGCAGGCTATGTCAG- ${ }^{\prime}$ and $5^{\prime}$-CATCAAAACTGGTTGCTTCAGCACTG - $3^{\prime}$; zRAG2, $5^{\prime}$ - TGAGACTCAGAAGCGCATGG- $3^{\prime}$ and $5^{\prime}$-ACCAAGTACGACTGTGGCTG-3'; and $\beta$-actin, 5'-GACGGCCAGGTCATCACTATTG-3' and 5'-AGGAAGGCTGGAAAAGAGCC-3' .

Recombination assay of plasmid substrate in NIH3T3 cells and HEK-293T cells. Recombinant pCJGFP (700 ng) or pSJGFP (700 ng) fluorescent substrate plasmids were cotransfected along with pEBG-RAG1 (1500 ng) and pEBG-RAG2 (1500 ng) or an equal amount of empty vector into HEK-293T cells by calcium phosphate precipitation or into NIH3T3 cells with Lipo6000 reagent (Beyotime) $)^{9,21,23,69,72}$. After $48 \mathrm{~h}$, the recombination products were detected based on the percentage of cell GFP expression with a FACSCalibur (BD) machine. Then, the data were analyzed with FlowJo.

Recombinant pJH289 (700 ng) or pJH290 (700 ng) substrate plasmids were cotransfected with pEBG-RAG1 (1500 ng) and pEBG-RAG2 (1500 ng) or an equal amount of empty vector into HEK-293T cells by calcium phosphate precipitation ${ }^{9,68,72}$. After $48 \mathrm{~h}$, the transfected DNA was extracted and purified with a GeneJET ${ }^{\mathrm{TM}}$ Genomic DNA Purification Kit. The assays for detection and analysis were performed as previously described ${ }^{68}$. The following primer pairs were used: for pJH289-SJ and pJH290-CJ, $5^{\prime}$-CCCCAGGCTTTACACTTT- $3^{\prime}$ and 5'-CCGTCTTTCATTGCCATAC-3'; for pJH289 and pJH290 input, 5' -TCTTTATAGTCCTGTCGGGTTT-3' and $5^{\prime}$-GCGGTAATACGGTTATCCAC-3'.

Immunoblot analysis. Cells were lysed on ice for $30 \mathrm{~min}$ in RIPA lysis buffer (Beyotime) with a protease inhibitor cocktail (Cell Signaling Technology, CST), and the lysates were cleared by centrifugation. The protein extracts were separated by SDS-PAGE and analyzed by immunoblotting with the indicated Abs and HRP-conjugated secondary Abs (Santa Cruz Biotechnology). Antibodies for $\beta$-actin were used at a dilution of 1:5000 (Multisciences (Lianke) Biotech, Co., Ltd.), and antibodies for GFP (sc-9996; Santa Cruz Biotechnology) were used at a dilution of 1:1000. The bands on the blots were visualized with an ECL kit (34096; Thermo).

Histology staining. Perfused lungs and livers from killed mice were dissected, fixed in $4 \%(\mathrm{v} / \mathrm{v})$ buffered neutral formalin and embedded in paraffin. Five-micron tissue sections were stained with hematoxylin and eosin. All images were acquired with an Olympus BX51 microscope and DP71 camera was used to acquire (Olympus).

Statistical analysis. For comparison between groups, all data are expressed as the mean $\pm \mathrm{SD}$. The results were analyzed by Student's $t$-test. A P value less than 0.05 was considered significant.

Received: 16 October 2019; Accepted: 19 February 2020;

Published online: 05 March 2020

\section{References}

1. Cooper, M. D. \& Alder, M. N. The evolution of adaptive immune systems. Cell 124, 815-822, https://doi.org/10.1016/j. cell.2006.02.001 (2006).

2. Flajnik, M. F. \& Kasahara, M. Origin and evolution of the adaptive immune system: genetic events and selective pressures. Nat. Rev. Genet. 11, 47-59, https://doi.org/10.1038/nrg2703 (2010).

3. Schatz, D. G. \& Swanson, P. C. V(D)J Recombination: Mechanisms of Initiation. Annu. Rev. Genet. 45, 167-202, https://doi. org/10.1146/annurev-genet-110410-132552 (2011).

4. Tonegawa, S. Somatic Generation of Antibody Diversity. Nat. 302, 575-581, https://doi.org/10.1038/302575a0 (1983).

5. Hedrick, S. M., Cohen, D. I., Nielsen, E. A. \& Davis, M. M. Isolation of Cdna Clones Encoding T-Cell-Specific Membrane-Associated Proteins. Nat. 308, 149-153, https://doi.org/10.1038/308149a0 (1984).

6. Lewis, S. M. The Mechanism of V(D)J Joining - Lessons from Molecular, Immunological, and Comparative Analyses. Adv. Immunology ume 56, 27-150, https://doi.org/10.1016/S0065-2776(08)60450-2 (1994).

7. Lovely, G. A. \& Sen, R. Evolving adaptive immunity. Gene Dev. 30, 873-875, https://doi.org/10.1101/gad.281014.116 (2016).

8. Huang, S. F. et al. Discovery of an Active RAG Transposon Illuminates the Origins of V(D)J Recombination. Cell 166, 102-114, https://doi.org/10.1016/j.cell.2016.05.032 (2016).

9. Zhang, Y. N. et al. An amphioxus RAG1-like DNA fragment encodes a functional central domain of vertebrate core RAG1. P Natl Acad. Sci. USA 111, 397-402, https://doi.org/10.1073/pnas.1318843111 (2014).

10. Carmona, L. M., Fugmann, S. D. \& Schatz, D. G. Collaboration of RAG2 with RAG1-like proteins during the evolution of V(D)J recombination. Gene Dev. 30, 909-917, https://doi.org/10.1101/gad.278432.116 (2016).

11. Litman, G. W., Cannon, J. P. \& Dishaw, L. J. Reconstructing immune phylogeny: New perspectives. Nat. Rev. Immunology 5, 866-879, https://doi.org/10.1038/nri1712 (2005).

12. Huxley, J. Cattle practice: ready to adapt to a changing world? Vet. Rec. 179, 377-381, https://doi.org/10.1136/vr.i5438 (2016)

13. Buchmann, K. Evolution of innate immunity: clues from invertebrates via fish to mammals. Front Immunol 5, https://doi. org/10.3389/fimmu.2014.00459 (2014).

14. Boehm, T. \& Swann, J. B. Origin and Evolution of Adaptive Immunity. Annu. Rev. Anim. Biosci. 2, 259-283, https://doi.org/10.1146/ annurev-animal-022513-114201 (2014).

15. Lieschke, G. J. \& Currie, P. D. Animal models of human disease: zebrafish swim into view. Nat. Rev. Genet. 8, 353-367, https://doi. org/10.1038/nrg2091 (2007).

16. Vaz, R. L., Outeiro, T. F. \& Ferreira, J. J. Zebrafish as an Animal Model for Drug Discovery in Parkinson's Disease and Other Movement Disorders: A Systematic Review. Front Neurol 9, https://doi.org/10.3389/fneur.2018.00347 (2018).

17. Perlman, R. L. Mouse models of human disease An evolutionary perspective. Evol Med Public Hlth, 170-176, https://doi. org/10.1093/emph/eow014 (2016).

18. Babiker, H. \& Tautz, D. Molecular and phenotypic distinction of the very recently evolved insular subspecies Mus musculus helgolandicus ZIMMERMANN, 1953. Bmc Evol Biol 15, https://doi.org/10.1186/s12862-015-0439-5 (2015).

19. Brazeau, M. D. \& Friedman, M. The origin and early phylogenetic history of jawed vertebrates. Nat. 520, 490-497, https://doi. org/10.1038/nature14438 (2015).

20. Guo, C. G. et al. CTCF-binding elements mediate control of V(D)J recombination. Nat. 477, 424-430, https://doi.org/10.1038/ nature10495 (2011). 
21. Giallourakis, C. C. et al. Elements between the IgH variable (V) and diversity (D) clusters influence antisense transcription and lineage-specific V(D)J recombination. P Natl Acad. Sci. USA 107, 22207-22212, https://doi.org/10.1073/pnas.1015954107 (2010).

22. Liu, Y., Subrahmanyam, R., Chakraborty, T., Sen, R. \& Desiderio, S. A plant homeodomain in Rag-2 that binds hypermethylated lysine 4 of histone $\mathrm{H} 3$ is necessary for efficient antigen-receptor-gene rearrangement. Immun. 27, 561-571, https://doi.org/10.1016/j. immuni.2007.09.005 (2007).

23. Schatz, D. G. \& Baltimore, D. Stable Expression of Immunoglobulin Gene V(D)J Recombinase Activity by Gene-Transfer into 3t3 Fibroblasts. Cell 53, 107-115, https://doi.org/10.1016/0092-8674(88)90492-8 (1988).

24. Ji, Y. H. et al. The In Vivo Pattern of Binding of RAG1 and RAG2 to Antigen Receptor Loci (vol 141, pg 419, 2010). Cell 143, 419-431, https://doi.org/10.1016/j.cell.2010.03.010 (2010).

25. Teng, G. et al. RAG Represents a Widespread Threat to the Lymphocyte Genome. Cell 162, 751-765, https://doi.org/10.1016/j. cell.2015.07.009 (2015).

26. Caldwell, R. G. \& Longnecker, R. Detection of immunoglobulin gene rearrangements. Methods Mol. Biol. 174, 423-431, https://doi. org/10.1385/1-59259-227-9:423 (2001).

27. Fistonich, C. et al. Cell circuits between B cell progenitors and IL-7(+) mesenchymal progenitor cells control B cell development. J. Exp. Med. 215, 2586-2599, https://doi.org/10.1084/jem.20180778 (2018).

28. Sfakianakis, D. G., Leris, I. \& Kentouri, M. Effect of developmental temperature on swimming performance of zebrafish (Danio rerio) juveniles. Env. Biol. Fish. 90, 421-427, https://doi.org/10.1007/s10641-010-9751-5 (2011).

29. Wang, Q., Tan, X., Jiao, S., You, F. \& Zhang, P. J. Analyzing cold tolerance mechanism in transgenic zebrafish (Danio rerio). PLoS One 9, e102492, https://doi.org/10.1371/journal.pone.0102492 (2014).

30. Kim, M. S., Lapkouski, M., Yang, W. \& Gellert, M. Crystal structure of the V(D)J recombinase RAG1-RAG2. Nat. 518, 507-511, https://doi.org/10.1038/nature14174 (2015).

31. Ru, H. et al. Molecular Mechanism of V(D)J Recombination from Synaptic RAG1-RAG2 Complex Structures. Cell 163, 1138-1152, https://doi.org/10.1016/j.cell.2015.10.055 (2015).

32. Rodgers, K. K. Riches in RAGs: Revealing the V(D)J Recombinase through High-Resolution Structures. Trends Biochem. Sci. 42, 72-84, https://doi.org/10.1016/j.tibs.2016.10.003 (2017).

33. Liu, P. T., Jenkins, N. A. \& Copeland, N. G. A highly efficient recombineering-based method for generating conditional knockout mutations. Genome Res. 13, 476-484, https://doi.org/10.1101/gr.749203 (2003).

34. Porporato, P. E. Understanding cachexia as a cancer metabolism syndrome. Oncogenesis 5, e200, https://doi.org/10.1038/ oncsis.2016.3 (2016)

35. Buck, M. D., Sowell, R. T., Kaech, S. M. \& Pearce, E. L. Metabolic Instruction of Immunity. Cell 169, 570-586, https://doi. org/10.1016/j.cell.2017.04.004 (2017).

36. Laine, A., Iyengar, P. \& Pandita, T. K. The Role of Inflammatory Pathways in Cancer-Associated Cachexia and Radiation Resistance. Mol. Cancer Res. 11, 967-972, https://doi.org/10.1158/1541-7786.Mcr-13-0189 (2013).

37. Villiger, P. M., Cronin, M. T., Amenomori, T., Wachsman, W. \& Lotz, M. Il-6 Production by Human Lymphocytes-T - Expression in Htlv-1-Infected but Not in Normal T-Cells. J. Immunol. 146, 550-559 (1991).

38. Acharyya, S. et al. Cancer cachexia is regulated by selective targeting of skeletal muscle gene products. J. Clin. Invest. 114, 370-378, https://doi.org/10.1172/jci200420174 (2004).

39. Langrish, C. L. et al. IL-23 drives a pathogenic T cell population that induces autoimmune inflammation. J. Exp. Med. 201, 233-240, https://doi.org/10.1084/jem.20041257 (2005).

40. Kimura, A. \& Kishimoto, T. IL-6: Regulator of Treg/Th17 balance. Eur. J. Immunol. 40, 1830-1835, https://doi.org/10.1002/ eji.201040391 (2010)

41. Mills, K. H. G. T. L. R.-dependent T cell activation in autoimmunity. Nat. Rev. Immunology 11, 807-822, https://doi.org/10.1038/ nri3095 (2011).

42. Tokuriki, N. \& Tawfik, D. S. Stability effects of mutations and protein evolvability. Curr. Opin. Struc Biol. 19, 596-604, https://doi. org/10.1016/j.sbi.2009.08.003 (2009).

43. Raman, A. S., White, K. I. \& Ranganathan, R. Origins of Allostery and Evolvability in Proteins: A Case Study. Cell 166, 468-480, https://doi.org/10.1016/j.cell.2016.05.047 (2016).

44. Saavedra, H. G., Wrabl, J. O., Anderson, J. A., Li, J. \& Hilser, V. J. Dynamic allostery can drive cold adaptation in enzymes. Nat. 558, 324-328, https://doi.org/10.1038/s41586-018-0183-2 (2018).

45. Goodey, N. M. \& Benkovic, S. J. Allosteric regulation and catalysis emerge via a common route. Nat. Chem. Biol. 4, 474-482, https:// doi.org/10.1038/nchembio.98 (2008).

46. Bettridge, J., Na, C. H., Pandey, A. \& Desiderio, S. H3K4me3 induces allosteric conformational changes in the DNA-binding and catalytic regions of the V(D)J recombinase. P Natl Acad. Sci. USA 114, 1904-1909, https://doi.org/10.1073/pnas.1615727114 (2017).

47. Swanson, P. C. \& Desiderio, S. RAG-2 promotes heptamer occupancy by RAG-1 in the assembly of a V(D)J initiation complex. Mol. Cell Biol. 19, 3674-3683, https://doi.org/10.1128/mcb.19.5.3674 (1999).

48. Schatz, D. G. \& Ji, Y. H. Recombination centres and the orchestration of V(D)J recombination. Nat. Rev. Immunology 11, 251-263, https://doi.org/10.1038/nri2941 (2011).

49. Kuriyan, J. \& Eisenberg, D. The origin of protein interactions and allostery in colocalization. Nat. 450, 983-990, https://doi. org/10.1038/nature06524 (2007).

50. Reynolds, K. A. \& Ranganathan, R. Hot spots for allosteric regulation on protein surfaces. Cell 147, 1564-75, https://doi. org/10.1016/j.cell.2011.10.049 (2011).

51. Gomez, C. A. et al. Mutations in conserved regions of the predicted RAG2 kelch repeats block initiation of V(D)J recombination and result in primary immunodeficiencies. Mol. Cell Biol. 20, 5653-5664, https://doi.org/10.1128/Mcb.20.15.5653-5664 (2000).

52. Teng, G. \& Schatz, D. G. Regulation and Evolution of the RAG Recombinase. Adv. Immunol. 128, 1-39, https://doi.org/10.1016/ bs.ai.2015.07.002 (2015).

53. Spence, R. et al. The distribution and habitat preferences of the zebrafish in Bangladesh. J. Fish. Biol. 69, 1435-1448, https://doi. org/10.1111/j.1095-8649.2006.01206.x (2006).

54. Parichy, D. M. Advancing biology through a deeper understanding of zebrafish ecology and evolution. Elife 4, e05635, https://doi. org/10.7554/elife.05635 (2015).

55. Engeszer, R. E., Patterson, L. B., Rao, A. A. \& Parichy, D. M. Zebrafish in the Wild: A Review of Natural History and New Notes from the Field. Zebrafish 4, 21-40, https://doi.org/10.1089/zeb.2006.9997 (2007).

56. Breen, M. S., Kemena, C., Vlasov, P. K., Notredame, C. \& Kondrashov, F. A. Epistasis as the primary factor in molecular evolution. Nat. 490, 535-538, https://doi.org/10.1038/nature11510 (2012).

57. Podgornaia, A. I. \& Laub, M. T. Pervasive degeneracy and epistasis in a protein-protein interface. Sci. 347, 673-677, https://doi. org/10.1126/science.1257360 (2015)

58. Sohail, M. et al. Negative selection in humans and fruit flies involves synergistic epistasis. Sci. 356, 539-542, https://doi.org/10.1126/ science.aah5238 (2017).

59. Phillips, P. C. Epistasis - the essential role of gene interactions in the structure and evolution of genetic systems. Nat. Rev. Genet. 9, 855-867, https://doi.org/10.1038/nrg2452 (2008).

60. Seebacher, F., Schwartz, T. S. \& Thompson, M. B. Transition from ectothermy to endothermy: the development of metabolic capacity in a bird (Gallus gallus). P Roy. Soc. B-Biol Sci. 273, 565-570, https://doi.org/10.1098/rspb.2005.3333 (2006). 
61. Ruben, J. The Evolution of Endothermy in Mammals and Birds - from Physiology to Fossils. Annu. Rev. Physiol. 57, 69-95, https:// doi.org/10.1146/annurev.ph.57.030195.000441 (1995).

62. Clarke, A. Costs and consequences of evolutionary temperature adaptation. Trends Ecol. Evol. 18, 573-581, https://doi.org/10.1016/j. tree.2003.08.007 (2003).

63. Angilletta, M. J. Estimating and comparing thermal performance curves. J. Therm. Biol. 31, 541-545, https://doi.org/10.1016/j. jtherbio.2006.06.002 (2006).

64. Igawa, T. et al. Evolutionary history of the extant amphioxus lineage with shallow-branching diversification. Sci. Rep-Uk 7, 1157, https://doi.org/10.1038/s41598-017-00786-5 (2017).

65. Notarangelo, L. D., Kim, M. S., Walter, J. E. \& Lee, Y. N. Human RAG mutations: biochemistry and clinical implications. Nat. Rev. Immunology 16, 234-246, https://doi.org/10.1038/nri.2016.28 (2016).

66. Couedel, C. et al. Analysis of mutations from SCID and Omenn syndrome patients reveals the central role of the Rag2 PHD domain in regulating V(D)J recombination. J. Clin. Invest. 120, 1337-1344, https://doi.org/10.1172/Jci41305 (2010).

67. Xu, K. et al. Disruption of the RAG2 zinc finger motif impairs protein stability and causes immunodeficiency. Eur. J. Immunol. 46, 1011-1019, https://doi.org/10.1002/eji.201545896 (2016).

68. Deng, Z. M., Liu, H. F. \& Liu, X. L. RAG1-mediated ubiquitylation of histone H3 is required for chromosomal V(D)J recombination. Cell Res. 25, 181-192, https://doi.org/10.1038/cr.2015.1 (2015).

69. Wang, X. M. et al. Regulation of Tcrb recombination ordering by c-Fos-dependent RAG deposition. Nat. Immunol. 9, 794-801, https://doi.org/10.1038/ni.1614 (2008).

70. Xiao, G., Deng, A. Q., Liu, H. F., Ge, G. X. \& Liu, X. L. Activator protein 1 suppresses antitumor T-cell function via the induction of programmed death 1. P Natl Acad. Sci. USA 109, 15419-15424, https://doi.org/10.1073/pnas.1206370109 (2012).

71. Xu, Y. et al. Regulation of the terminal maturation of iNKT cells by mediator complex subunit 23. Nat Commun 9, https://doi. org/10.1038/s41467-018-06372-1 (2018).

72. Corneo, B. et al. Rag mutations reveal robust alternative end joining. Nat. 449, 483-486, https://doi.org/10.1038/nature06168 (2007).

\section{Acknowledgements}

We thank the Stem Cell Bank, Chinese Academy of Sciences for ES cell targeting. We also thank Baojin Wu and Guoyuan Chen for the animal husbandry and Wei Bian for cell sorting. This work was supported by grants from National Natural Science Foundation of China (31621003, 31530021, 31500717, and 31501193), the Strategic Priority Research Program of the Chinese Academy of Sciences (Grant XDB19000000), the Youth Innovation Promotion Association of Chinese Academy of Sciences and National Key R\&D Program of China (2017YFA0506700).

\section{Author contributions}

A.S., K.X. and X.L. designed research; A.S., K.X., H.F.L., Y.S., X.Z., T.L. X.C. and X.Y.L. performed research; Y.J., H.L., T.J. and C.X. contributed new reagents/analytic tools; A.S., K.X., H.L. and Y.S. analyzed data; and A.S., K.X., C.X. and X.L. wrote the paper.

\section{Competing interests}

The authors declare no competing interests.

\section{Additional information}

Supplementary information is available for this paper at https://doi.org/10.1038/s41598-020-61019-w.

Correspondence and requests for materials should be addressed to X.L.

Reprints and permissions information is available at www.nature.com/reprints.

Publisher's note Springer Nature remains neutral with regard to jurisdictional claims in published maps and institutional affiliations.

(c) (i) Open Access This article is licensed under a Creative Commons Attribution 4.0 International cc. License, which permits use, sharing, adaptation, distribution and reproduction in any medium or format, as long as you give appropriate credit to the original author(s) and the source, provide a link to the Creative Commons license, and indicate if changes were made. The images or other third party material in this article are included in the article's Creative Commons license, unless indicated otherwise in a credit line to the material. If material is not included in the article's Creative Commons license and your intended use is not permitted by statutory regulation or exceeds the permitted use, you will need to obtain permission directly from the copyright holder. To view a copy of this license, visit http://creativecommons.org/licenses/by/4.0/.

(C) The Author(s) 2020 